\title{
Studi Analisa Ekonomi Pabrik CPO (Crude Palm Oil) dan PKO (Palm Kernel Oil) Dari Buah Kelapa Sawit
}

\author{
Novia Larasati, Siti Chasanah, Siti Machmudah, dan Sugeng Winardi \\ Jurusan Teknik Kimia, Fakultas Teknologi Industri, Institut Teknologi Sepuluh Nopember (ITS) \\ Jl. Arief Rahman Hakim, Surabaya 60111 Indonesia \\ e-mail: sitimach@chem-eng.its.ac.id
}

\begin{abstract}
Abstrak- Kelapa sawit merupakan salah satu komoditi utama yang mempengaruhi pertumbuhan ekonomi Indonesia. Industri pengolahannya memberikan kontribusi yang penting dalam menghasilkan devisa dan lapangan pekerjaan. Hal tersebut dikarenakan minyak kelapa sawit merupakan industri hulu yang sangat penting bagi berbagai industri lainnya, seperti: makanan, kosmetik, sabun dan cat. Bahkan akhir-akhir ini ada upaya penggunaan minyak kelapa sawit sebagai bahan baku pembuatan bahan bakar alternatif. Kondisi ini memacu perkembangan industri pengolahan kelapa sawit, baik kebutuhan dalam negeri maupun ekspor. Dan perkembangan industri sejalan dengan semakin meningkatnya luas areal perkebunan kelapa sawit. Kapasitas produksi kelapa sawit direncanakan sebesar 237.600 Ton/tahun. Perencanaan ini berdasarkan jumlah lahan yang dimiliki oleh pabrik. Dalam pemenuhan kapasitas tahunan, pabrik akan beroperasi kontinyu 24 jam per hari selama 330 hari Untuk memproduksi CPO sebesar 89.742 ton/tahun diperlukan bahan baku TBS 237.600 ton/tahun, $\mathrm{CO}_{2} 199$ ton/tahun dan propan 9 ton/tahun. Selain CPO, pabrik ini juga menghasilkan produk berupa Palm Kernel Oil (PKO) yang dihasilkan sebanyak 9.338 ton/tahun. Dari perhitungan analisa ekonomi, dengan harga jual CPO sebesar \$562 per ton dan harga PKO sebesar \$810 diperoleh Internal Rate Return (IRR) sebesar 45\%. Dengan IRR tersebut mengindikasikan bahwa pabrik layak untuk didirikan dengan suku bunga $12 \%$ dan waktu pengembalian modal (pay out period) selama 2,6 tahun. Perhitungan analisa ekonomi didasarkan pada discounted cash flow. Modal untuk pendirian pabrik menggunakan rasio $60 \%$ modal sendiri dan $40 \%$ modal pinjaman. Modal total yang dibutuhkan untuk mendirikan pabrik adalah sebesar Rp. 211.001.470.206 dan laba bersih yaitu sebesar Rp. 112.838.149.952. Sedangkan Break Event Point (BEP) yang diperoleh adalah sebesar 36,53\%.
\end{abstract} PKO.

Kata Kunci- Desain Pabrik, Buah Kelapa Sawit, CPO,

\section{PENDAHULUAN}

$\mathrm{B}$ UAH sawit adalah sumber bahan baku.CPO (Crude Palm Oil) dan PKO (Palm Kernel Oil). CPO dihasilkan dari daging buah sawit, sedangkan PKO dihasilkan dari inti buahnya. Sebuah alternatif sumber bahan baku potensial yang cukup banyak tersedia telah muncul, yaitu produk samping biomassa non-kelas pangan buah kelapa sawit dan produksi minyak sawit. Ini bukanlah sekedar menggunakan minyak dari buah kelapa sawit, melainkan mengkonversi seluruh biomassa yang diambil dari perkebunan kelapa sawit menjadi sumber energi terbarukan. Dengan menggunakan biomassa dari perkebunan maupun sisa pengolahan dari produksi minyak sawit (serat, kulit, efluen pabrik minyak sawit, minyak sisa, dsb).
Perkembangan selanjutnya adalah muncul pemikiran bahwa ekspor Crude Palm Oil dan Palm Kernel Oil akan sangat menguntungkan produsen minyak sawit mentah di Indonesia. Hal tersebut didukung dengan kapasitas produksi minyak sawit Indonesia yang cukup besar. Selain itu, permintaan pasar dunia yang terus meningkat akan minyak sawit serta ditunjang dengan banyaknya produk olahan yang merupakan turunan dari produksi Crude Palm Oil dan Palm Kernel Oil. Kenaikan harga minyak sawit mentah merupakan sebuah rangsangan utama bagi para pengusaha di Indonesia, adapun usaha peningkatan produksi kelapa sawit hingga saat ini terus dilakukan, baik secara intensifikasi maupun ekstensifikasi. Selain itu akan membuka lapangan kerja yang lebih luas dan akan mendorong berkembangnya industri minyak mentah (Crude Palm Oil dan Palm Kernel Oil) yang lebih adaptif dan inovatif. Selain itu perlunya penerapan strategi dalam mengahadapi persaingan pasar minyak CPO dan PKO. Dari aspek ekonomi, harganya relatif murah dibandingkan dengan olahan minyak nabati lainnya. Produksi Crude Palm Oil dan Palm Kernel Oil di Indonesia tahun 2013 mencapai 26 juta ton atau naik 1,9\% dibanding 2012 sebanyak 26,5 juta ton. Sedangkan produksi 2014 jumlahnya di kisaran 27,5-28 juta ton. Sedangkan harga minyak sawit mentah (Crude Palm Oil) dan produk turunannya di pasar internasional mampu menembus US\$ 1.100 per ton. Hal itu berpotensi mendongkrak ekspor CPO hingga ke level US\$ 24,2 miliar [1].

Strategi yang diterapkan untuk menghadapi persaingan pasar minyak CPO dan PKO erat kaitannya dengan kegiatan pemasaran. Dalam hal ini pola dan strategi pemasaran selalu ditinjau ulang, sebaran penjualan produk diutamakan pada daerah yang memberikan margin laba usaha optimal melalui program optimasi distribusi sehingga daerah pemasaran dan pola angkutan disesuaikan. Untuk mendapatkan kinerja penjualan yang maksimal, fokus wilayah penjualan adalah di pasar domestik. Sesuai dengan keunggulan geografis, di mana pabrik direncanakan didirikan di daerah Riau. Untuk mendapatkan harga dengan profit margin optimal maka manajemen harus menerapkan sinergi distribusi dan penjualan. Pihak manajemen melalui bagian distribusi juga mengelola pasokan ke setiap wilayah pasar baik domestik maupun ekspor agar memberikan nilai tambah yang paling besar, dengan memperhatikan pasokan dari pabrik sehingga menghasilkan efisiensi beban distribusi, peningkatan utilisasi kapasitas packing, alokasi ekspor apabila kapasitas pabrik memungkinkan. Untuk itu perlu dilakukannya analisa ekonomi terhadap pendirian pabrik CPO (Crude Palm Oil) 
dan PKO (Palm Kernel Oil) berbahan dasar buah kelapa sawit dengan melihat besarnya potensi pengembangan CPO dan PKO di Indonesia.

\section{URAIAN PROSES}

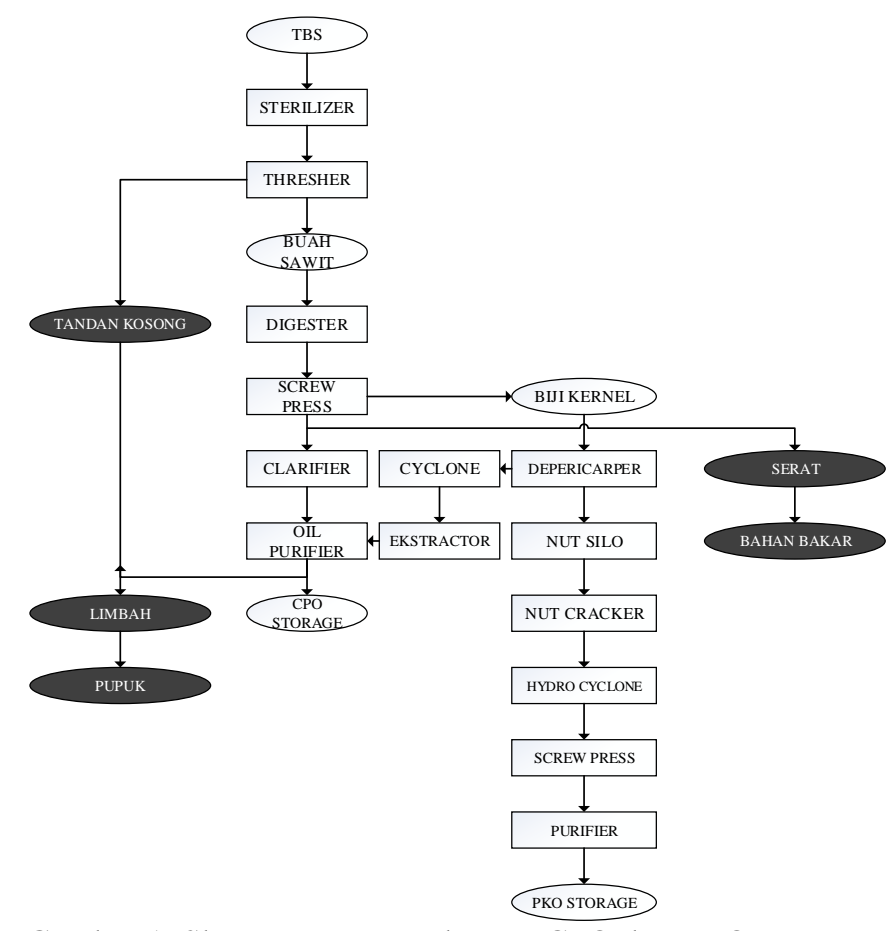

Gambar 1. Skema Proses pembuatan CPO dan PKO

\section{A. Pengolahan $\mathrm{CPO}$}

Proses awal dimulai dengan penyiapan bahan baku TBS yang diambil dari perkebunan sawit. TBS yang sudah diangkut oleh truck ditempatkan di loading ramp. Tandan Buah Segar dari loading ramp ini kemudian dimasukkan kedalam lori-lori yaitu tempat meletakkan buah kelapa sawit untuk proses perebusan yang berkapasitas 3,75 ton Tandan Buah Segar pada setiap lorinya. Tandan Buah Segar yang dimasukkan kedalam lori dengan membuka pintu loading ramp yang diatur dengan sistem hidrolik.Pengolahan kelapa sawit menjadi CPO diawali dengan proses perebusan TBS ke dalam sterilizer bertipe horizontal tank. Kemudian buah yang telah masak dimasukkan ke dalam thresser untuk proses pemisahan antara tandan kosong dan daging buah sawit. Dari tempat tersebut buah sawit yang terpisah dari tandan kosong dimasukkan ke digester dan diaduk sedemikian rupa sehingga sebagian besar daging buah sudah terlepas dari biji.

Selanjutnya proses pengadukan dan pelumatan buah lebih lanjut akan menghasilkan bubur buah yang mengandung minyak. Minyak bebas dibiarkan keluar secara kontinu melalui lubang dasar digester. Massa yang keluar dari digester diperas dalam screw press pada tekanan30-50Bar dengan kondisi screw press bersuhu $90-95^{\circ} \mathrm{C}$. Setelah proses pengepresan untuk selanjutnya adalah proses penyaringan memakai vibrating screenbertujuan untuk memisahkan Nonoil Solid (NOS) yang berukuran besar seperti serabut, pasir, tanah, kotoran-kotoran lain yang terbawa dengan minyak.

Minyak yang keluar dari vibrating screen ke crude oil tank untuk ditampung sementara sebelum dipompakan ke stasiun pemurnian. Dari sini minyak dipompakan ke cylinder setting tankuntuk mengendapkan lumpur, pasir, dengan perbedaan berat jenisnya dan waktu pengendapannya, maka minyak yang mempunyai densitasnya lebih ringan, maka akan terapung ke permukaan bagian atas CST. Minyak dari CST menuju ke pure oil tank untuk ditampung sementara waktu, sebelum dialirkan ke oil purifier. Minyak yang keluar darioil purifier masih mengandung air, maka untuk mengurangi kadar air tersebut, minyak melalui pompa oil purifierdipompakan ke vacum dryerdengan tipe spray dryer. Sludge yang masih mengandung minyak pada bagian CST di alirkan ke sludge oil tank untuk pengendapan lumpur, sludge kembali dan dipanaskan dengan suhu 80-90 ${ }^{\circ} \mathrm{C}$. Dengan menggunakan sistem coil untuk memudahkan pemisahan lumpur, air dan minyak

Minyak setelah melalui alat pengering (vacum dryer) dengan mutu standar melalui pompa oil transfer pump, kemudian dipompakan ke storage tank, dengan suhu sampai $45-60^{\circ} \mathrm{C}$. Setiap hari dilakukan pengujian mutu minyak sawit. Minyak yang dihasilkan dari daging buah ini berupa minyak kasar atau disebut juga Crude Palm Oil (CPO)

\section{B. Pengolahan PKO}

Selanjutnya pengolahan minyak inti sawit atau biasa disebut Palm Kernel Oil (PKO) melalui beberapa tahapan, tahap awal adalah Ampas kempa dari screw press yang terdiri dari serat dan biji yang masih mengempal masuk ke screw conveyor. Alat ini berfungsi memindahkan fiber dan kernel menuju ke alat pemisahan yang disebut depericarper. Depericarper adalah alat untuk memisahkan ampas dengan biji serta memisahkan biji dari sisa-sisa serabut yang masih melekat pada biji dengan bantuan 2 buah blower untuk mendorong atau menghempaskan serat ke atas yang kemudian akan masuk ke dalam cyclone. Serat (ampas) akan dipisahkan dari debu dan kotoran lain maupun mengurangi kadar air yang terdapat dalam ampas/seratdengan menggunakan cyclone untuk kemudian ampas yang diperoleh diproses kembali didalam metode Fraksinasi $\mathrm{CO}_{2}$ super kritisatau Super Critical Fluid Extraction (SCFE) untuk mengambil atau mengekstrak sisa minyak yang masih terkandung dalam ampas.

Fraksinasi ini dilakukan untuk mengambil jumlah minyak yang masih terdapat di ampas.Upaya ini dilakukan agar menghasilkan produk minyak CPO lebih banyak dan meminimalisir minyak yang terbuang.CPO yang telah dipisahkan dari ampasnya dilakukan proses pemurnian lebih lanjut melalui CPO Purification. CO2 digunakan kembali dengan menghilangkan kandungan air melalui proses absorpsi terlebih dahulu. Lalu dikondisikan dengan tekanan tertentu agar bisa di recycle kembali dengan menggunakan pompa sentrifugal sebagai alat transfernya menuju kolom ektraksi.

Proses selanjutnya menuju ke nut silo, fungsi dari alat ini adalah untuk tempat pemeraman biji. Hal ini dilakukan untuk mengurangi kadar air sehingga lebih mudah dipecah dan inti lekang dari cangkangnya.nut silo juga berfungsi untuk menurunkan pengaruh pectin (yang berfungsi sebagai lem perekat) yang terdapat antara cangkang dan inti. Dari nut silo masuk ke nut crackeryakni dengan tipe hammer mill untuk memecah inti kernel sehingga inti terpisah dari cangkang. Biji yang masuk melalui bagian atas rotor akan mengalami gaya sentrifugal sehingga biji keluar dari rotor dan terbanting kuat 
yang menyebabkan inti pecah.

Selanjutnya masuk ke dalam hydro cyclone, berfungsi sebagaialat pemisah inti dengan cangkang dengan menggunakan media air. Proses pemisahan ini secara basah dengan memanfaatkan berat jenis dari bahan yang dipisahkan diantara kedua bahan tersebut. Bagian yang ringan akan mengapung dan bagian yang berat akan tenggelam. Inti yang merupakan fraksi ringan akan dibawa ke nut dryer untuk mengurangi kadar air. Inti yang telah melalui proses pengeringan selanjutnya di press dalam screw press dengan tipe press roller mill. Cara kerjanya adalah bahan masuk melalui bagian tengah lalu kemudian 2 buah roller akan bergerak berlawanan arah sehingga menjepit bahan dan menjadi bahan hancur.Setelah didapat minyak PKO kemudian di murnikan dalam proses purifikasi. Produk PKO setelah melalui alat palm kernel oil purifier dengan mutu standar melalui pompa oil transfer pump, kemudian dipompakan ke storage Tank [2].

\section{HASIL ANALISA EKONOMI}

Analisa ekonomi merupakan salah satu parameter apakah suatu pabrik tersebut layak didirikan atau tidak. Untuk menentukan kelayakan suatu pabrik secara ekonomi, diperlukan perhitungan bahan baku yang dibutuhkan dan produk yang dihasilkan. Berdasarkan perhitungan neraca massa dengan menggunakan bahan baku Tandan Buah Segar (TBS) yang memiliki komposisi buah sawit sebesar 60,46\%, dan tandan kosong 39,54\%. Buah sawit memiliki komponen mesocarp sebesar $78,4 \%$ yang terdiri dari minyak $77,43 \%$, air $10 \%$, dan serat $12,57 \%$. Selain itu buah sawit juga mengandung cangkang sebesar $12,6 \%$ dan inti buah sebesar $9 \%$. Untuk tandan kosong itu sendiri mempunyai komposisi tandan kosong sebesar 70\% dan lumpur sebesar 30\%. Dengan komposisi yang terkandung dalam buah kelapa sawit mampu memproduksi CPO sebesar 89.742 ton/tahun dengan kapasitas perancangan pabrik sebesar 237.600 ton/tahun. Selain CPO, pabrik ini juga menghasilkan produk berupa Palm Kernel Oil (PKO) yang dihasilkan sebanyak 9.338 ton/tahun dengan menggunakan ekstraksi CO2 super kritis untuk pengambilan minyak yang terkandung dalam ampas kelapa sawit, yakni mesocarp yang telah di press namun masih terdapat kandungan minyaknya sekitar 5\%. Untuk ekstraksi $\mathrm{CO} 2$ super kritis diperlukan $\mathrm{CO} 2$ super kritis sebanyak 199 ton/tahun dan propan 9 ton/tahun sebagai pendigin dalam chiller.

Untuk melakukan evaluasi atau studi kelayakan dan penilaian investasi untuk pendirian pabrik CPO dan $\mathrm{PKO}$ maka dilakukan peninjauan terhadap faktor-faktor Laju Pengembalian Modal ( Internal Rate of Return / IRR), Waktu Pengembalian Modal Minimum ( Pay Out Time / POT ),

Titik Impas ( Break Even Point / BEP ). Dimana menggunakan asumsi bahwa pabrik kelapa sawit ini akan didirikan dan siap beroperasi pada tahun 2020, dengan pembelian peralatan pada tahun 2017 dan masa konstruksi selama 2 tahun (2018-2019).

Laju Pengembalian Modal(Internal Rate of Return/IRR)

Laju pengembalian Modal adalah suatu tingkat bunga tertentu dimana seluruh penerimaan kan tepat menutup total modal yag dikeluarkan dengan menghitung trial harga laju bunga (i), dimana laju bunga yang memenuhi persamaan berikut [3]:

$$
\sum \frac{C F}{(1+i)^{n}}=\text { Total modal akhir di masa konstruksi }
$$

$$
\text { Dimana, } \begin{aligned}
& \mathrm{n}=\text { Tahun } \\
& \mathrm{CF}=\text { Cash Flow tahun ke-n } \\
&(1+\mathrm{i}) \mathrm{n}=\text { Discounted Factor } \\
& \text { Tabel 1. Daftar Trial Laju Bunga (i) }
\end{aligned}
$$

\begin{tabular}{cccc}
\hline \hline \multirow{2}{*}{$\begin{array}{c}\text { Tahun } \\
\text { ke-n }\end{array}$} & $\begin{array}{c}\text { Net Cash Flow } \\
(\mathrm{Rp})\end{array}$ & \multicolumn{2}{c}{$\mathrm{i}=45 \%$} \\
\cline { 3 - 4 } & & $(1+\mathrm{i})^{\mathrm{n}}$ & Present Value $(\mathrm{Rp})$ \\
\hline 1 & 59.634 .778 .427 & 1,455 & 40.989 .746 .479 \\
2 & 83.766 .861 .280 & 2,117 & 39.575 .233 .629 \\
3 & 107.898 .944 .133 & 3,079 & 35.038 .383 .487 \\
4 & 108.604 .544 .964 & 4,480 & 24.240 .997 .641 \\
5 & 109.310 .145 .795 & 6,518 & 16.770 .213 .237 \\
6 & 110.015 .746 .627 & 9,48 & 11.601 .351 .463 \\
7 & 110.721 .347 .458 & 13,80 & 8.025 .289 .690 \\
8 & 111.426 .948 .289 & 20,1 & 5.551 .306 .603 \\
9 & 112.132 .549 .120 & 29,2 & 3.839 .832 .635 \\
10 & 112.838 .149 .952 & 42,5 & 2.655 .902 .817 \\
& Total (Rp.) & & 188.288 .257 .682
\end{tabular}

Dari hasil perhitungan didapatkan harga $\mathrm{i}=45 \%$. Harga $\mathrm{i}$ yang diperoleh lebih besar dari harga i untuk bunga pinjaman yaitu $12 \%$ per tahun. Dengan harga $\mathrm{IRR}=45 \%$ yang didapatkan dari perhitungan menunjukkan bahwa pabrik ini layak didirikan dengan kondisi tingkat bunga pinjaman $12 \%$ per tahun.

\section{A. Waktu Pengembalian Modal ( Pay Out Time / POT)}

Waktu Pengembalian Modal adalah untuk menghitung waktu pengembalian modal, maka dihitung akumulasi modal sebagai berikut :

\begin{tabular}{ccc}
\multicolumn{3}{c}{ Tabel 2. Daftar Akumulasi Cash Flow } \\
\hline \hline $\begin{array}{c}\text { Tahun } \\
\text { ke-n }\end{array}$ & $\begin{array}{c}\text { Net Cash Flow } \\
(\mathrm{Rp})\end{array}$ & Cummulative Cash Flow (Rp) \\
\hline 1 & 59.634 .778 .427 & 59.634 .778 .427 \\
2 & 83.766 .861 .280 & 143.401 .639 .707 \\
3 & 107.898 .944 .133 & 251.300 .583 .840 \\
4 & 108.604 .544 .964 & 359.905 .128 .805 \\
5 & 109.310 .145 .795 & 469.215 .274 .600 \\
6 & 110.015 .746 .627 & 579.231 .021 .227 \\
7 & 110.721 .347 .458 & 689.952 .368 .685 \\
8 & 111.426 .948 .289 & 801.379 .316 .974 \\
9 & 112.132 .549 .120 & 913.511 .866 .095 \\
10 & 112.838 .149 .952 & 1.026 .350 .016 .046 \\
\hline \hline
\end{tabular}

Untuk investasi akhir dimasa konstruksi sebesar Rp.211.001.470.206 dan dengan dilakukan interpolasi pada Tabel 2 maka didapatkan waktu pengembalian modal pada tahun ke 2 dan 3. Sehingga dari perhitungan yang dilakukan didapatkan bahwa waktu pengembalian modal minimum adalah 2,6 tahun. Hal ini menunjukkan bahwa pabrik ini layak untuk didirikan karena POT yang didapatkan lebih kecil dari 
perkiraan usia pabrik.

\section{B. Titik Impas ( Break Even Point / BEP )}

Analisa titik impas digunakan untuk mengetahui besarnya jumlah kapasitas produksi dimana biaya produksi total sama dengan hasil penjualan. Biaya tetap (FC) dan Biaya variabel (VC), Biaya semi variabel (SVC) dan biaya total tidak dipengaruhi oleh kapasitas produksi seperti grafik dibawah ini:

Tabel 3. Daftar Biaya FC, VC, SVC, dan S

\begin{tabular}{|c|c|c|}
\hline No & Keterangan & Jumlah \\
\hline 1 & Biaya Tetap $(F C)$ & Rp 25.607.203.045 \\
\hline \multirow[t]{5}{*}{2} & Biaya Variabel $(V C)$ & \\
\hline & - Bahan baku & Rp 332.976.992.887 \\
\hline & - Utilitas & Rp 104.830.866.113 \\
\hline & - Pengemasan & $\operatorname{Rp} 0,0$ \\
\hline & Total & Rp 437.807.859.000 \\
\hline \multirow[t]{9}{*}{3} & Biaya Semi Variabel $(S V C)$ & \\
\hline & - Tenaga kerja & Rp 14.754.000.000 \\
\hline & - Pengawasan & Rp 1.770 .480 .000 \\
\hline & - Pemeliharaan dan perbaikan & Rp 16.004.501.903 \\
\hline & - Suplai operasi & Rp 1.600.450.190 \\
\hline & - Laboratorium & Rp 2.213.100.000 \\
\hline & - Biaya umum $(G E)$ & Rp132.302.835.716 \\
\hline & - Biaya overhead (POC) & Rp 17.890.940.047 \\
\hline & Total & Rp186.536.307.856 \\
\hline 4 & Total penjualan $(S)$ & Rp791.676.181.296 \\
\hline
\end{tabular}

Dari data pada Tabel 3 maka dapat digunakan untuk membuat grafik BEP.

Tabel 4. Data untuk membuat grafik BEP

\begin{tabular}{cccc}
\hline \hline Kapasitas & $0 \%$ & & $100 \%$ \\
\hline $\begin{array}{c}\text { Biaya tetap } \\
\text { Pengeluaran }\end{array}$ & $\mathrm{Rp} 25.607 .203 .045$ & $\mathrm{Rp}$ & 25.607 .203 .045 \\
$\begin{array}{c}\text { total } \\
\text { Penjualan } \\
\text { Total }\end{array}$ & $\mathrm{Rp}$ 81.568.095.402 & $\mathrm{Rp}$ & 649.951 .369 .901 \\
\hline \hline
\end{tabular}

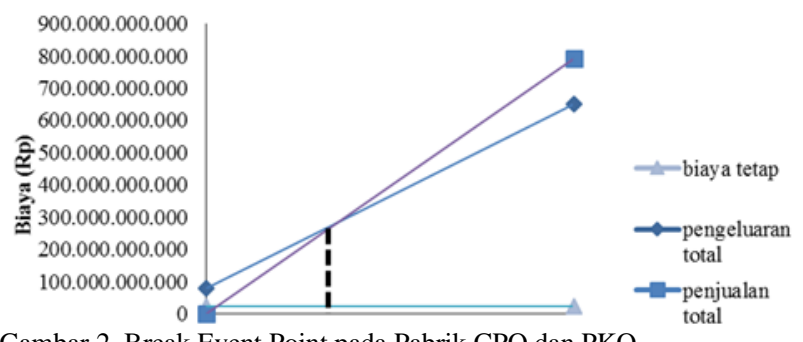

Gambar 2. Break Event Point pada Pabrik CPO dan PKO

Dari perhitungan yang dilakukan didapatkan bahwa Titik Impas $(\mathrm{BEP})=36,53 \%$.

\section{KESIMPULAN}

Dari hasil analisa ekonomi pabrik CPO dan PKO dari buah kelapa sawit didapatkan IRR $45 \%$ yang mengindikasikan bahwa pabrik layak untuk didirikan dengan suku bunga $12 \%$ dan waktu pengembalian modal (pay out period) selama 2,6 tahun. Perhitungan analisa ekonomi didasarkan pada discounted cash flow. Dengan modal untuk pendirian pabrik menggunakan rasio $60 \%$ modal sendiri dan $40 \%$ modal pinjaman. Modal total yang dibutuhkan untuk mendirikan pabrik adalah sebesar Rp. 211.001.470.206 dan laba bersih yaitu sebesar Rp. 112.838.149.952. Sedangkan Break Event Point (BEP) yang diperoleh adalah sebesar $36,53 \%$.

\section{DAFTAR PUSTAKA}

[1] Badan Pusat Statistik. 2014. Statistik Kelapa Sawit Indonesia. Badan Pusat Satistik Indonesia.

[2] Naibaho, P.M. 1996. Teknologi Pengolahan Kelapa Sawit. Pusat Penelitian Kelapa Sawit. Medan.

[3] Peters, Max S. and Timmerhaus, Klaus D., 1991 "Plant Design and Economic for Chemical Engineering 4-ed", International Edition. Singapore: McGraw-Hill Book Co. Singapore

[4] Perry, H. Robert. 1997."chemical Engineering Handbook 7th". New York: McGraw-Hill. 